\title{
A macroeconomia da crise e as oportunidades do Brasil
}

\author{
João Basílio Pereima Neto* \\ Geraldo Augusto Staub Filho**
}

RESUMO - Este artigo discute os impedimentos externos que atuarão no sentido de travar o crescimento brasileiro, os impedimentos internos e por fim as vantagens comparativas que o país possui para enfrentar a crise mundial por conta de sua conjuntura macroeconômica e posse de alguns ativos estratégicos importantes. $\mathrm{O}$ artigo encerra concluindo pela necessidade do Brasil caminhar o rumo ao desenvolvimento, soberanamente. O país poderá transformar a crise em oportunidade se atentar a um passado recente, quando conquistas importantes foram precedidas de crises, como na década de 1930 com Getúlio Vargas, 1950 com Juscelino Kubischek e 1970 com o II Plano Nacional de Desenvolvimento.

Palavras-chave: Macroeconomia. Crescimento. Crise.

\section{INTRODUÇÃO}

O presente ciclo de crescimento econômico observado no Brasil (2003-2008) entrará em fase crítica a partir de 2009. Encerra-se a fase de crescimento puxado pelo mundo, período em que o país cresceu ao reboque da economia mundial, e inicia-se uma fase que colocará em cheque as propriedades endógenas do crescimento da economia brasileira. Mais do que nunca o país deverá exercer sua vontade soberana, como Nação que sabe o que quer e não como país navega sem rumo ao sabor dos ventos da economia mundial, como tem acontecido. Este artigo discute os impedimentos externos que atuarão no sentido de travar o crescimento brasileiro, os impedimentos internos e por fim as vantagens comparativas que o país possui para enfrentar a crise mundial por conta de sua conjuntura macroeconômica e posse de alguns ativos estratégicos importantes. $\mathrm{O}$ artigo encerra concluindo pela necessidade do Brasil caminhar o rumo ao desenvolvimento, soberanamente. O país poderá transformar a crise em oportunidade se atentar a um passado recente, quando conquistas importantes foram precedidas de crises, como na década de 1930 com Getúlio Vargas, 1950 com Juscelino Kubischek e 1970 com o II Plano Nacional de Desenvolvimento. Estes foram momentos cruciais de inflexão histórica e moldaram o país que somos hoje. Eles foram possíveis graças à visão abrangente e posturas ousadas dos governos e sociedade de então. Para tanto criatividade e algumas mudanças são necessárias.

\footnotetext{
* Doutorando do Programa de Pós-Graduação em Desenvolvimento Econômico da UFPR e Professor assistente do Departamento de Economia da mesma instituição. Endereço eletrônico: joaobasilio@ufpr.br.

** Bacharel em Direito, mestrando do Programa de Pós-Graduação em Desenvolvimento Econômico da UFPR e integrante da equipe do Boletim de Economia e Tecnologia. Endereço eletrônico: gutostaub@yahoo.com.br.
} 


\section{IMPEDIMENTOS EXTERNOS}

Os desdobramentos de crise econômica terão um efeito prolongado sobre a economia mundial. A recessão que atinge as principais economias industrializadas ao final de 2008 poderá transformar-se em grave e duradoura depressão. Este cenário se torna cada vez mais visível à medida que o tempo passa e novos eventos são anunciados. Neste contexto os principais impedimentos externos ao crescimento brasileiro são: a) queda na demanda mundial de países industrializados e em desenvolvimento, inclusive asiáticos; b) queda nos preços das commodities; c) tendência de aumento de práticas mercantilistas por conta da dificuldade de levar adiante modelos de crescimento baseado em exportações; d) redução da liquidez internacional, o que pode impedir o refinanciamento de investimentos privados internos com recursos baratos captados no exterior.

Efeito quantum e efeito preços das exportações. A desaceleração dos países industrializados terá um grande efeito nas taxas de crescimento dos países emergentes e será mais contundente nos países que adotam modelos de crescimento econômico impulsionados pelas exportações, como no caso mexicano e asiático e especialmente na China. No caso específico das relações entre China-EUA, a China usa seus elevados superávits comerciais para comprar títulos do governo americano ${ }^{31}$ financiando assim parte dos seus déficits gêmeos: externo e fiscal. $O$ interesse da China e demais países asiáticos em aplicar suas reservas em títulos americanos reside no fato de que isto ajuda a financiar as próprias exportações e assim viabiliza seu modelo de crescimento.

Neste sentido a alegação de que o Brasil irá se ressentir menos com a crise em 2009 porque diversificou sua pauta de exportações, diminuindo a importância da economia americana na pauta, não é verdadeira. As relações simbióticas entre EUA e asiáticos superavitários fazem com que a crise seja global. Os países asiáticos irão reduzir drasticamente suas exportações, colocando em cheque seus modelos de crescimento econômico, com reflexos imediatos em sua capacidade e necessidade de importar as commodities brasileiras. $\mathrm{O}$ efeito quantum e o efeito preço das exportações que atuou favoravelmente ao Brasil nos últimos anos vão atuar contra a partir de agora. Mesmo com uma pauta mais diversificada entre países o setor externo será fortemente afetado, pois os maiores importadores das commodities brasileiras são exatamente os países industrializados e os asiáticos.

\footnotetext{
${ }^{31}$ A China possui uma empresa denominada CIC - China Investment Corporation - para administrar as reservas internacionais das Pessoas da República da China, das quais uma boa parte está aplicada em títulos do governo americano.
} 
Práticas Mercantilistas. A tese básica de enriquecimento das nações da teoria mercantilista, que foi objeto de crítica na obra A Riqueza das Nações de Adam Smith em 1776, era de que os países que conseguissem exportar mais e importar menos seriam os mais ricos. A base das exportações seriam seus excedentes que, à época, eram basicamente produtos agrícolas e derivados. O enriquecimento adviria então do fluxo de ouro para dentro do país exportador, que era então a forma disponível para acumular reservas internacionais. A estratégia mercantilista para inserção internacional era adotar práticas agressivas de estímulo as vendas e barreiras às compras externas. A principal crítica de Smith à economia mercantilista foi de que a fonte de enriquecimento não é propriamente a atividade comercial, mas sim a capacidade de produção e a tecnologia que criava internamente valor, através da divisão e especialização do trabalho. A fonte de riqueza era a produtividade do trabalho, obtida pela sua divisão e especialização. O comércio era conseqüência da geração de valor excedente na etapa da produção, anterior àquela. Deste modo, para Adam Smith o crescimento econômico viria por meio de fontes endógenas.

Os países asiáticos, especialmente a China, adotaram nos últimos 30 anos modelos de crescimento baseados em exportação, juntando o que havia de melhor nos dois mundos, o mercantilista e o industrial. Utilizaram uma política cambial pró-exportação e fomentaram a indústria nacional baseada em tecnologia. Administraram suas taxas de câmbio e fizeram do mundo seu mercado. Para que estes modelos de crescimento tenham sucesso é necessário que os outros países admitam déficits em transações correntes. Alguém tem que pagar a conta. Quando todos os países crescem, fica mais fácil para os países industrializados importadores suportarem os déficits em transações correntes, pois compensam o desemprego gerado pelas importações, com o próprio crescimento econômico. Não há conflito interno pois a economia está crescendo. Neste cenário os modelos baseados em exportações funcionam bem, contudo o aprofundamento da crise colocará em cheque estes regimes de crescimento. Com o objetivo de combater o desemprego, que se aprofunda no fim de 2008, os países industrializados deverão necessariamente adotar medidas econômicas que protejam a geração local de emprego. A solução para os industrializados passa por estimular a indústria local ao mesmo tempo em que se criam mais barreiras ao comércio. Poderia se argumentar que mais comércio internacional, mais abertura e menor protecionismo legal e cambial seria de fato a solução, e não o contrário. Acontece que os países em desenvolvimento que dependem de exportação estão tendo seus mercados reduzidos drasticamente por um problema de insuficiência de demanda. Para não verem suas taxas de crescimentos caírem com mais 
intensidade terão intensificar seus esforços exportadores o que inclui mais práticas protecionistas e câmbios competitivos. Por outro lado os países desenvolvidos terão que reforçar suas próprias políticas a fim de evitar o mercantilismo agressivo adotados pelos exportadores. A questão essencial é que a crise mundial mudou a matriz de benefícios (pay-offs) do atual jogo de interesses. As práticas mercantilistas tendem a recrudescer.

Falta de liquidez. Outro grave impedimento externo ao crescimento dos países em desenvolvimento é a forte retração de liquidez. Países em desenvolvimento enfrentam um problema estrutural que é a escassez de recursos financeiros para o financiamento de longo prazo. O Brasil tentou lidar com o problema da falta de crédito através de alguns mecanismos de criação de poupança interna de cunho forçado. A instituição do FGTS em 1967, a criação do BNDES com recursos públicos, as práticas de vendas casadas de bens com compra de ações adotadas pelas empresas estatais de comunicação no passado, foram todos exemplos desta criativa solução dentro de uma economia pobre cuja propensão marginal á consumir é elevada.

A enorme destruição de riqueza financeira pela crise colocará em cheque os diversos mecanismos e canais pelos quais os recursos financeiros mundiais circulavam entre empresas produtivas, governos e mercados financeiros nos países em desenvolvimento. As ramificações e entrelaçamentos entre diversas atividades econômicas, praças financeiras e instrumentos sofisticados de crédito e propriedade fazem com que os efeitos da crise se alastrem por vários segmentos e países colocando em cheque diversos canais de financiamento que davam sustentação tanto ao giro dos negócios quanto aos investimentos de longo prazo.

Países com mercados financeiros pouco desenvolvidos e com sistemas de poupança frágeis e insuficientes, e que recorrem à poupança externa com fonte de financiamento, terão um desafio adicional para enfrentar a crise e proteger suas taxas de crescimento econômico.

\section{IMPEDIMENTOS INTERNOS}

No que se refere aos impedimentos internos do crescimento, o Brasil enfrenta uma situação particular, por conta de certas propriedades de sua estrutura produtiva e governança macroeconômica. Os principais impedimentos a nosso ver são: a) vulnerabilidade externa não resolvida; b) regime macroeconômico que favorece a volatilidade cambial; c) excessiva participação do capital estrangeiro em todos os setores da economia; d) Banco Central e taxa de juros.

Vulnerabilidade externa. O Banco Central brasileiro ainda mantém, mesmo depois de sucessivas ofertas ao mercado realizadas nos meses de outubro e novembro, um nível de 
reservas em moeda estrangeira bastante alta para o padrão brasileiro. Cerca de US\$ 195 bilhões estavam disponíveis para o governo central no início de dezembro para o controle do câmbio e até mesmo para financiar as exportações, no caso de uma violenta restrição interna ao crédito. Apesar do enorme esforço do governo ${ }^{32}$ para adquirir e manter o atual nível reservas observa-se a partir da Tabela 1 que este indicador não é tão alto como propalado se confrontado com o de outros países:

TABELA 1 - PIB E RESERVAS INTERNACIONAIS - OUT/2008 (US\$ milhões)

\begin{tabular}{l|r|r|r}
\hline \multicolumn{1}{c|}{ País } & PIB 2008 estimado & Reservas & Reservas \% PIB \\
\hline Argentina & 338.721 & 47.121 & $13,91 \%$ \\
Brasil & 1.664 .662 & 195.556 & $11,75 \%$ \\
Chile & 181.464 & 24.204 & $13,34 \%$ \\
China & 4.222 .423 & 2.045 .000 & $48,43 \%$ \\
Cingapura $*$ & 161.347 & 162.173 & $100,51 \%$ \\
Colômbia $*$ & 171.978 & 23.241 & $13,51 \%$ \\
Coréia do Sul & 953.489 & 212.253 & $22,26 \%$ \\
Hong Kong $*$ & 206.705 & 154.849 & $74,91 \%$ \\
Índia & 1.237 .445 & 86.336 & $23,14 \%$ \\
Malásia $*$ & 180.713 & 100.214 & $55,45 \%$ \\
Rússia & 1.778 .693 & 484.590 & $27,24 \%$ \\
Uruguai $*$ & 23.086 & 5.999 & $25,99 \%$ \\
\hline
\end{tabular}

FONTE: FMI, elaborado pelos autores.

* NOTA: PIB 2007.

Os países asiáticos, que adotam um modelo de crescimento puxado por exportações, possuem altos volumes de reservas internacionais como proporção do PIB. Cingapura, Hong Kong e Malásia mantêm, respectivamente, 100,51\%, 74,91\% e 55,45\% do PIB em reservas, números realmente impressionantes. A gigante China possui a maior reserva em dólares do mundo, o maior valor absoluto na Tabela 1 com US\$2,045 trilhões. Mesmo comparado aos níveis de reserva de outros países da América do Sul o Brasil está em desvantagem. Os vizinhos Argentina e Uruguai possuem 13,91\% e 25,99\% de seus produtos internos em reservas, respectivamente, enquanto Chile e Colômbia apresentam este índice em 13,34\% e 13,51\%. Completando os BRICS, a Índia possui reservas na ordem de US\$86,336 bilhões, 23,14\% do PIB, e Rússia US\$ 484,59 bilhões, representando 27,24\% de seu produto interno.

Outro motivo de preocupação é o enorme passivo privado e público apresentado pelo Brasil em sua Conta Financeira. A tabela 2 a seguir mostra a posição de estoque de capital estrangeiro no país versus o capital brasileiro no estrangeiro. O país tem um passivo

\footnotetext{
32 Vale frisar que o acúmulo de reservas por um país faz parte de um esforço fiscal enorme, tanto para aquisição quanto para manutenção. O custo fiscal destes títulos é a diferença entre a rentabilidade do título possuído (de governos estrangeiros, remunerado em dólar a taxas internacionais, não mais do que 5\% na média) e o custo de captação, que é, basicamente, a taxa SELIC, hoje em 13,75\%.
} 
descoberto em relação ao resto do mundo de US\$ 574 bilhões. Este passivo foi 3,19 vezes maior que as reservas internacionais de US\$ 180 bilhões, em 2007.

TABELA 2 - PASSIVO E ATIVO EXTERNO, BRASIL: 2007 (US\$ bilhões, final do ano)

\begin{tabular}{l|r|r}
\hline Contas & Resultado & \% \\
\hline Posição (A-B) & $\mathbf{- 5 7 4}$ & $\mathbf{- 6 1 , 1 \%}$ \\
Ativo (A) & $\mathbf{3 6 5}$ & $\mathbf{3 8 , 9 \%}$ \\
Investimento direto brasileiro no exterior & 130 & $\mathbf{1 3 , 8} \%$ \\
Investimentos em carteira & 15 & $1,6 \%$ \\
Outros investimentos e derivativos & 39 & $4,2 \%$ \\
Ativos de reservas & 180 & $19,2 \%$ \\
Passivo (B) & $\mathbf{9 3 9}$ & $\mathbf{1 0 0 , 0} \%$ \\
Investimento estrangeiro direto & 328 & $34,9 \%$ \\
Participação no capital & 281 & $29,9 \%$ \\
Empréstimo intercompanhia & 47 & $5,0 \%$ \\
Investimento em carteira & 510 & $54,3 \%$ \\
Investimentos em ações & 364 & $38,8 \%$ \\
$\quad$ No país & 166 & $17,7 \%$ \\
$\quad$ No exterior & 198 & $21,1 \%$ \\
Títulos de renda fixa & 146 & $15,5 \%$ \\
$\quad$ No exterior & 99 & $10,5 \%$ \\
$\quad$ No país & 47 & $5,0 \%$ \\
Outros investimentos e derivativos & 101 & $10,8 \%$ \\
\hline
\end{tabular}

FONTE: BACEN.

Além do passivo descoberto há um problema de estrutura do passivo. O investimento em carteira representa 54,3\% das reservas existentes em 2007. Tendo em vista que este tipo de capital está apenas interessado em especulação no mercado ações e operações de arbitragem de juros por conta do hiato entre juros nacional e mundial é 2,83 vezes maior que as reserva de 2007, de forma que a vulnerabilidade externa do Brasil está longe de ser um problema resolvido, o que explica a volatilidade cambial observada.

Volatilidade cambial. A inexistência de recursos para o controle do câmbio aliada a taxas de juros altíssimas (ainda mais em um cenário de queda generalizada a nível mundial), fez com que o Real desvalorizasse sobremaneira nos meses de outubro, novembro e dezembro. Desde $1^{\circ}$ de agosto até 11 de dezembro a moeda apresentou desvalorização de $50,05 \%$, a maior dentre as economias relevantes. Se os ganhos com o câmbio poderiam servir de colchão para os exportadores frente a queda da demanda, a alta volatilidade apresentada no último período é um obstáculo relevante para o planejamento e bom manejo de caixa para as empresas que tenham tanto receitas como custos em moeda estrangeira. As incertezas e expectativas do mercado estão afetando mais fortemente a volatilidade câmbio do que o movimento de oferta e procura de moeda (Gráfico 1). No dia 11 de dezembro, por exemplo, o valor do dólar em reais atingiu $\mathrm{R} \$ 2,3397$, o que representa uma baixa de 5,21\% em apenas 
um dia, interrompendo a série de alta de quase uma semana. O dia foi marcado por anúncios de ajudas do governo a grandes empresas e redução de impostos, notadamente IOF, IR e IPI. Os mesmos movimentos foram também observados com o anúncio de auxílio às montadoras (aqui e nos EUA), e na divulgação de pacotes de crédito mundo afora. O país não tem conseguido evitar uma excessiva volatilidade do câmbio ao longo deste crise e tem sofrido mais que outras economias.

GRÁFICO 1 - DÓLAR AMERICANO VENDA (PTAX) E RESERVAS INTERNACIONAIS (CONCEITO LIQUIDEZ TOTAL)

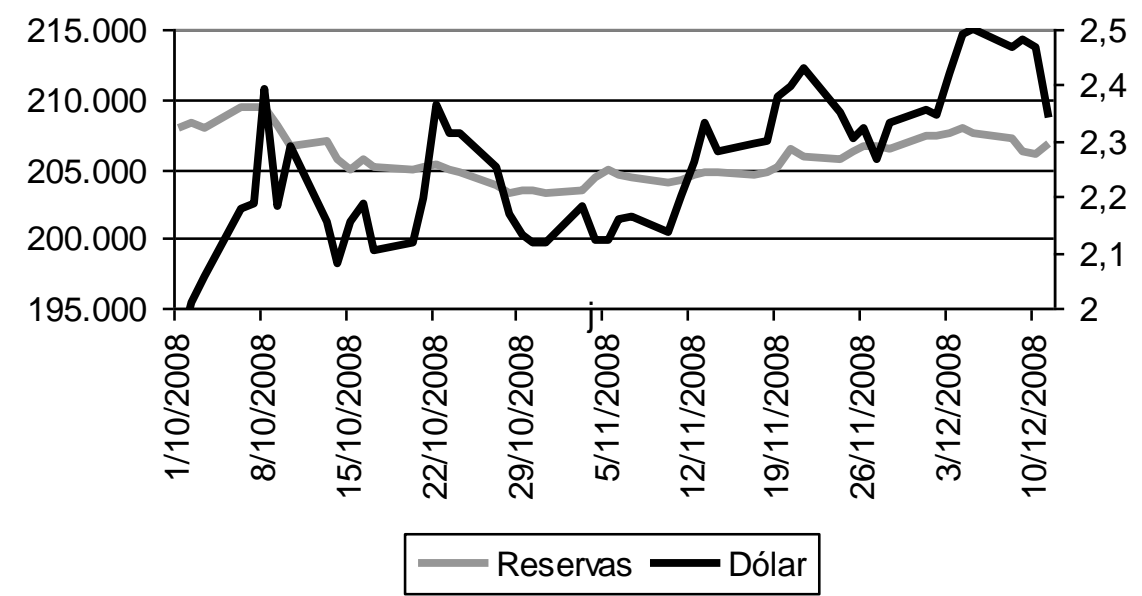

FONTE: Banco Central, elaborado pelos autores.

Capital Estrangeiro. O nível de investimentos diretos externos (investimentos no setor produtivo) que o Brasil recebeu em 2008 foi recorde: até o fim de novembro o país já tinha recebido US $\$ 37,1$ bilhões, superando a meta do Banco Central, estipulada em US\$ 35 bilhões para o ano de 2008 inteiro. Mas ao mesmo tempo remeteu US\$32,1 bilhões na forma de lucros e dividendos, compensando totalmente o fluxo. A elevada participação do capital estrangeiro com proporção do PIB não reflete apenas o movimento de concentração próprio da economia capitalista mundial, mas a prática quase rotineira adotada pelo país de financiar constantemente os déficits em conta corrente com atração de capital na forma de investimento estrangeiro direto. Uma considerável proporção de inúmeros setores produtivos é controlada por ou possui participação de estrangeiros. Os recursos de investimentos que ajudaram a movimentar a economia no ano de 2008 podem ter outros destinos em 2009. Com dificuldades de caixa e financiamento, grandes companhias do todo o mundo já apresentam planos de corte de investimentos. O fluxo de investimento estrangeiro pode se reduzir drasticamente em 2009 e anos seguintes, como o fez muitas vezes no passado, ao 
mesmo tempo em que a elevada remessa de lucros e dividendos continuará alta, levando à um agravamento do balanço de pagamentos.

Banco Central e taxas de juros. Não bastassem as fragilidades internas aqui comentadas teremos sérias e graves dificuldades se persistirem o conservadorismo e a lentidão do Banco Central na reação da política monetária. Não é recente a repetida postura da autoridade monetária em não atentar para os problemas do setor produtivo, preferindo sempre fazer o jogo do mercado financeiro. A demora e timidez da política monetária no ciclo de baixa dos juros de 2006, e também a falta de agressividade em um momento bastante favorável à baixa como o das últimas duas reuniões do COPOM, é um sinal do desequilíbrio da política atualmente adotada. Ao invés consolidar a reputação de independência da autoridade monetária, a assimetria da política monetária nos momentos em que é preciso reduzir a taxa de juros, faz exatamente o contrário. A assimetria da política monetária é tal que o banco central tem sido agressivo e exagerado nas altas e passivo e leniente nas baixas. Este comportamento introduz um viés no comportamento da autoridade monetária, exercido tanto em termos de timing quanto de nível de taxa de juros. Apesar da projeção baixista manifestada pelo próprio mercado, que tem reduzido sistematicamente os juros DI e rebaixado a curva da estrutura a termo da taxa de juros desde novembro de 2008, nas última duas reuniões o COPOM manteve inalterada a política monetária recusando-se baixar a taxa de juros. Uma decisão errada em termos de timing e de direção.

O viés da autoridade monetária em conjunto com os problemas do setor externo, impedem que a taxa de juros no Brasil seja menor. Se esta combinação permanecer ao longo dos próximos anos, o impacto da crise financeira será muito maior no Brasil do que até o momento tem sido imaginado pelo governo.

\section{VANTAGENS COMPARATIVAS}

A despeito dos problemas de governança macroeconômica, $\mathrm{O}$ Brasil possui algumas vantagens que podem ser usadas a seu favor durante o período de crise. O desenvolvimento histórico e a evolução recente da economia brasileira conduziram o país a uma posição estratégica diferenciada e privilegiada para enfrentar a crise. As vantagens comparativas do Brasil podem ser desmembradas em duas grandes categorias: uma diz respeito à posse de ativos estratégicos, que constituem as variáveis estruturantes para o desenvolvimento brasileiro, e que se reúnem num mesmo local, como em nenhum outro caso no mundo; a outra são as vantagens oferecidas pela conjuntura macroeconômica. 


\subsection{ATIVOS ESTRATÉGICOS: ENERGIA, ALIMENTOS, INSUMOS, MERCADO E TECNOLOGIA}

O Brasil é um dos poucos países do mundo que possuem cinco características que podem garantir um crescimento econômico sustentado de longo prazo: energia, alimentos, insumos, mercado interno (população) e tecnologia. Sem precisar fechar-se ao restante do mundo o desenvolvimento econômico brasileiro pode ser obtido a partir de um processo engendrado internamente. A posse de tais ativos cria as condições necessárias e facilitam a adoção de um modelo de crescimento voltado para dentro, menos dependente da economia mundial. Quando as condições externas mudarem, o que não ocorrerá em breve, o mercado internacional poderá voltar a ser explorado com mais intensidade, mas por ora as condições mundiais são adversas, pelo que se justifica a mobilização dos ativos estratégicos com mais vigor do que vem sendo feito. A questão essencial é não virar as costas para o mundo, mas deslocar o eixo de acumulação do capital sem criar dependência exterior. A importância de tais ativos estratégicos cresce como alternativa, num momento em que a economia mundial se retrai.

\subsection{CONJUNTURA MACROECONÔMICA}

Além dos cinco pilares para um crescimento sustentado, existem elementos de ordem macroeconômica no Brasil que podem ser explorados favoravelmente para manter sua taxa de crescimento. O país possui um superávit fiscal elevado, uma relação dívida bruta/PIB de 49,0\% e em queda. Do ponto de vista do endividamento público as finanças públicas estão, grosso modo, em ordem. No que se refere ao setor privado também. Via de regra as empresas e as famílias no Brasil utilizam-se pouco do mecanismo do crédito para consumo e investimento, de modo que a economia opera com baixo grau de alavancagem. Isto sempre foi visto pelos economistas como um problema e uma deficiência. Mas agora isto se converte numa grande vantagem. A redução momentânea de crédito em alguns segmentos da economia, ao contrário do resto do mundo, não é um problema grave para o Brasil. Como a relação crédito/PIB é pequena, atingindo apenas 38\% do PIB, variações no crédito tendem a não causar ciclos econômicos ampliados. O país sofreria muito com restrições de liquidez no mercado de crédito, caso a relação crédito/PIB fosse maior, como nos países que apresentam uma relação acima de $100 \%$.

Outro aspecto favorável do país é que o grau de abertura comercial é relativamente menor, se comparado a outras economias em desenvolvimento, como no caso dos países asiáticos. Os dados da Tabela 3 ilustram esse argumento. 
TABELA 3 - GRAU DE ABERTURA COMERCIAL * $2007(\%)$

\begin{tabular}{lr}
\hline \multicolumn{1}{c|}{ País } & (\%) \\
\hline Argentina & 38 \\
Brasil & 22 \\
Chile & 70 \\
China & 66 \\
Cingapura & 349 \\
Colômbia & 36 \\
Coréia do Sul & 75 \\
Hong Kong & 349 \\
Índia & 31 \\
Malásia & 179 \\
Rússia & 45 \\
Uruguai & 43 \\
\hline
\end{tabular}

FONTE: Banco Mundial, elaborado pelos autores.

NOTA: Grau de Abertura = $($ Exportações + Importações $) /$ PIB

Os países asiáticos optaram por uma modelo de crescimento puxado pelas exportações (export led-growth) que funcionou por um bom período. O coeficiente de abertura ${ }^{33}$ destes países é alto e sua dependência do dinamismo da economia mundial é muito grande. Cingapura, Hong Kong e Malásia são os exemplos mais claros. Pequenas variações na renda mundial, especialmente dos países desenvolvidos, causam grandes ciclos de negócios nas economias tipo export led-growth. Felizmente este não é o caso brasileiro, contando com o mais baixo índice dos países apresentados, 22\%, o Brasil, apesar das reformas liberalizantes da década de 90, ainda não ampliou significativamente sua rede de comércio internacional. Até países notoriamente protecionistas como Argentina e Índia possuem maiores relações comerciais como proporção do PIB e estão, portanto, mais expostas à crise de demanda na economia mundial.

É claro que a balança comercial e o saldo em transações correntes do Brasil vão sofrer os efeitos da recessão mundial. Até mesmo neste ponto, novamente o país possui vantagens. O parque industrial brasileiro é grande e diversificado e a indústria de bens de capital e bens de consumo durável está consolidada. A capacidade desta indústria em responder aos desafios do crescimento foi posta à prova neste ciclo dos últimos cinco anos, e apresentou elevadas taxas de expansão. Ao longo do ciclo de crescimento recente (20032007), aproveitando a valorização cambial, as empresas aumentaram a importação de bens de capital e substituíram fornecedores locais de peças por fornecedores estrangeiros, especialmente asiáticos. A indústria aproveitou a ocasião para modernizar os equipamentos. Com a virada cambial o movimento tende a se inverter. Ao invés de importar equipamentos e insumos, a indústria será estimulada novamente a recorrer ao mercado interno colocando em

\footnotetext{
${ }^{33}$ Soma do fluxo total exportações mais importações divididos pelo PIB.
} 
movimento uma força endógena de crescimento que até então estava sendo desviada, por estímulo cambial, para o resto do mundo. Um movimento semelhante ao que ocorreu na Crise de 1929, quando a volatilidade cambial ajudou a consolidar a indústria paulista.

Além da situação fiscal confortável, da baixa relação crédito/PIB e do baixo coeficiente de abertura comercial, um quarto elemento que joga a favor da endogenia do crescimento brasileiro é a interrupção do ciclo de alta dos preços em geral. É possível inclusive que nos próximos meses seja registrada uma queda dos preços de bens de consumo e bens duráveis, desde que não ocorra um overshooting na taxa de cambio por conta de movimentos de capitais intensos e uma especulação contra as reservas. A reversão da inflação abrirá um espaço (mais um) para que o Banco Central reduza finalmente a taxa nominal de juros do país.

A redução da taxa de juros, no caso brasileiro, não é importante apenas pelo fato de baratear o crédito ao consumo e ao investimento, mas também e principalmente por aliviar o orçamento do setor público. Uma baixa da taxa nominal de juros para $7 \%$ ou $8 \%$ permitirá que o país programe uma política de redução de impostos e ao mesmo tempo mantenha o orçamento em equilíbrio e até mesmo superavitário. Poderá inclusive injetar mais liquidez na economia resgatando dívida pública e reduzindo mais rapidamente a relação dívida/PIB.

Enfim, esta crise financeira mundial está revelando oportunidades históricas únicas para que o Brasil implemente de uma vez por todas um processo sustentado de crescimento econômico que lhe permita reduzir as desigualdades sociais e regionais que perseguem o país a décadas.

\section{CONCLUSÃO}

O contexto mundial e nacional exige do país uma guinada em termos de economia política. É necessário criar uma agenda chamada Brasil. Uma agenda que é muito maior do que um simples Plano de Aceleração do Crescimento, que nos últimos cinco anos tem sido mais do mesmo. O debate entre o continuísmo de um programa econômico levado pela maré e uma alternativa de desenvolvimento duradouro e com vistas aos interesses nacionais está posto. A vontade de uma nação é que deve ditar os destinos do país e não a instabilidade permanente que reina nas economias capitalistas. No nosso entender são urgentes e necessárias mudanças nas políticas macroeconômicas que incluam a centralização do câmbio e o controle de capitais (não confundir com fechamento da economia e cambio fixo, que são medidas muito mais extremas e inadequadas), a recuperação do controle do Estado sobre a política monetária e mudanças na condução da política fiscal. Esta última deve pautar-se pela 
adoção de políticas tributárias progressivas, contribuindo para uma melhor distribuição de renda, pela retomada da capacidade de investimento do Estado e por uma gestão eficiente e arrojada da dívida pública, através da recompra de títulos enquanto os juros estão altos e o valor presente de mercado dos títulos está baixo.

\section{REFERÊNCIAS}

SISTEMA GERENCIADOR DE SÉRIES TEMPORAIS (SGS). Brasília: Banco Central Do Brasil em: <http://www.bcb.gov.br >. Acesso em 17/12/2008. 